\title{
Sex differences in COVID-19: the role of androgens in disease severity and progression
}

\author{
Mohamed S. Mohamed ${ }^{1} \cdot$ Thiago C. Moulin $\mathbb{1}^{1} \cdot$ Helgi B. Schiöth ${ }^{1,2}$
}

Received: 28 August 2020 / Accepted: 24 October 2020 / Published online: 11 November 2020

(c) The Author(s) 2020

\begin{abstract}
Purpose Throughout the SARS-CoV2 pandemic, multiple reports show higher percentages of hospitalization, morbidity, and mortality among men than women, indicating that men are more affected by COVID-19. The pathophysiology of this difference is yet not established, but recent studies suggest that sex hormones may influence the viral infectivity process. Here, we review the current evidence of androgen sensitivity as a decisive factor for COVID-19 disease severity.

Methods Relevant literature investigating the role of androgens in COVID-19 was assessed. Further, we describe several drugs suggested as beneficial for COVID-19 treatment related to androgen pathways. Lastly, we looked at androgen sensitivity as a predictor for COVID-19 progression and ongoing clinical trials on androgen suppression therapies as a line of treatment.

Results SARS-COV2 virus spike proteins utilize Transmembrane protease serine 2 (TMPRSS2) for host entry. Androgen receptors are transcription promoters for TMPRSS2 and can, therefore, facilitate SARS-COV2 entry. Variants in the androgen receptor gene correlate with androgen sensitivity and are implicated in diseases like androgenetic alopecia and prostate cancer, conditions that have been associated with worse COVID-19 outcomes and hospitalization.

Conclusion Androgen's TMPRSS2-mediated actions might explain both the low fatalities observed in prepubertal children and the differences between sexes regarding SARS-COV2 infection. Androgen sensitivity may be a critical factor in determining COVID-19 disease severity, and sensitivity tests can, therefore, help in predicting patient outcomes.
\end{abstract}

Keywords SARS-COV2 $\cdot$ Testosterone $\cdot$ Nitric oxide $\cdot$ Hydroxychloroquine $\cdot$ Dexamethasone $\cdot$ CAG repeats

\section{Introduction}

The novel coronavirus disease (COVID-19) caused by severe acute respiratory syndrome coronavirus 2 (SARS-COV2) has evolved into a global pandemic and has affected millions of people worldwide. Two notably consistent findings are the low rates of prepubertal mortality [1] and that men are more likely to have severe symptoms and therefore need hospitalization $[1,2]$. Moreover, sex differences in the prevalence of smoking, cardiovascular diseases, and drinking habits do not fully account for the higher risks for men [2]. Likewise, disparities between sexes have also been observed in the Middle East

Thiago C. Moulin

thiago.moulin@neuro.uu.se

1 Functional Pharmacology Unit, Department of Neuroscience, Uppsala University, Uppsala, Sweden

2 Institute for Translational Medicine and Biotechnology, Sechenov First Moscow State Medical University, Moscow, Russia respiratory syndrome epidemic, where variation sex hormones were shown to rave a role in the disease susceptibility [3]. Androgens, such as testosterone and dihydrotestosterone, are steroid hormones produced in both sexes, and their levels increase with puberty. Androgens levels are higher in males than females and have been hypothesized to have a role in COVID-19 diseases [2, 4]. The interest in the role of androgens increased after the uncovering of SARS-COV2 entry points [5]. Following that, studies have shown that androgens have a role in COVID-19 disease progression and that a considerable number of hospitalized patients have an underlying androgen-mediated condition [6, 7]. In this review, we will look at how androgens facilitate SARS-COV2 entry, their role in disease progression, and their therapeutic value.

\section{The role of androgens is mediated by TMPRSS2}

The spike proteins of SARS-COV2 intermediate the entry to host cells by undergoing spike protein priming by the 
transmembrane protease serine 2 (TMPSS2) and by binding to Angiotensin-converting enzyme 2 (ACE2) receptors [5]. Data from prostate cancer research has demonstrated the androgen receptor as a regulator of TMPRSS2, capable of increasing the expression of this gene [8]. For example, the TMPRSS2 plays a role in the pathophysiology of prostate cancer by interacting with the oncogenic transcription factor ERG. The interaction between these genes juxtaposes the androgen receptor elements present in their code, causing the ERG gene to be also controlled by androgen receptor signalling [9]. The androgen-dependent nature is also evident outside of the prostate, as administering exogenous androgen treatment to a human lung adenocarcinomaderived cell line is able to increase expression of TMPRSS2, mainly in the in type II pneumocytes [10].

Moreover, androgen deprivation therapy (ADT), a commonly-used treatment for prostate cancer patients, has been shown to lower TMPRSS2 expression [11]. The proposed mechanism behind this effect is based on the idea that androgen receptor and, subsequently, TMPPRSS2 expression affects the SARS-COV2 virus ability to enter host cells and its spike proteins affinity to bind ACE2 receptors (Fig. 1). Therefore, ADT shows the potential to provide partial protection from SARS-CoV2 infections, while measuring androgen levels might be useful for the prognosis of COVID-19 severity. Nevertheless, further preclinical and clinical studies are needed for a better understanding of the androgen receptor effects and possible therapeutic applications.

\section{Androgen sensitivity and COVID-19 disease severity}

All androgens act through the androgen receptor, which is encoded by a single-copy gene on the $\mathrm{X}$ chromosome (Fig. 1), and variants of this gene correlate with different levels of androgen sensitivity. Such modifications increase the risk of androgen-mediated diseases such as androgenic alopecia and prostate cancer [12-14]. Evidence of androgen sensitivity association with COVID-19 disease progression can, therefore, be observed in such conditions. For example, androgenetic alopecia, a form of male pattern hair loss, is present in a substantial number of hospitalized patients [7] and was shown as a risk factor for developing severe COVID-19 symptoms [6]. Moreover, prostate cancer patients who take ADT seem to have a lower risk of COVID-19 infection compared to cancer patients without ADT [11].

However, the relationship between circulating androgen levels, androgen sensitivity, and COVID-19 severity is not straightforward. As androgens promote androgen receptor transcriptional activity, it would be expected that

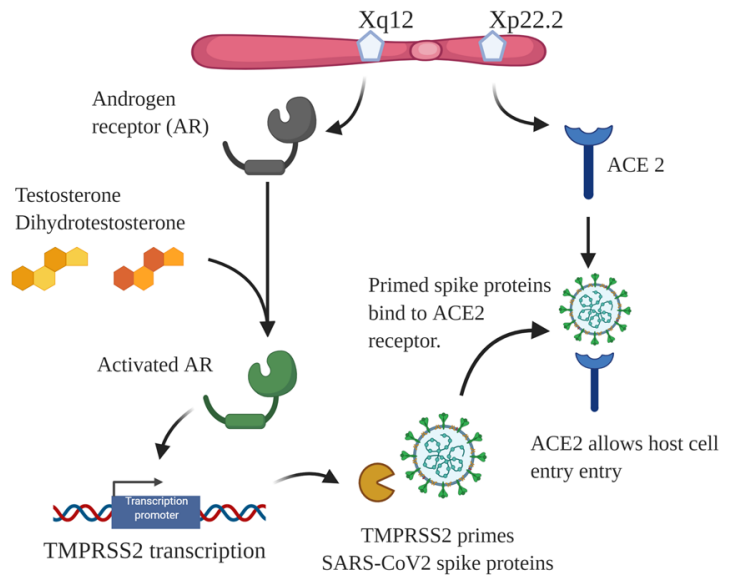

Fig. 1 Androgens facilitate SARS-COV2 entry through a TMPRSS2mediated pathway. Both androgen receptor and ACE2 genes are located on chromosome X. Circulating androgens binds to AR, activating it, which promotes TMPRSS2 transcription. SARS-CoV2 spike proteins are then primed by TMPRSS2, allowing the interaction with ACE2 receptors to enter host cells

\section{CAG repeats and COVID-19 severity: Proposed mechanisms}

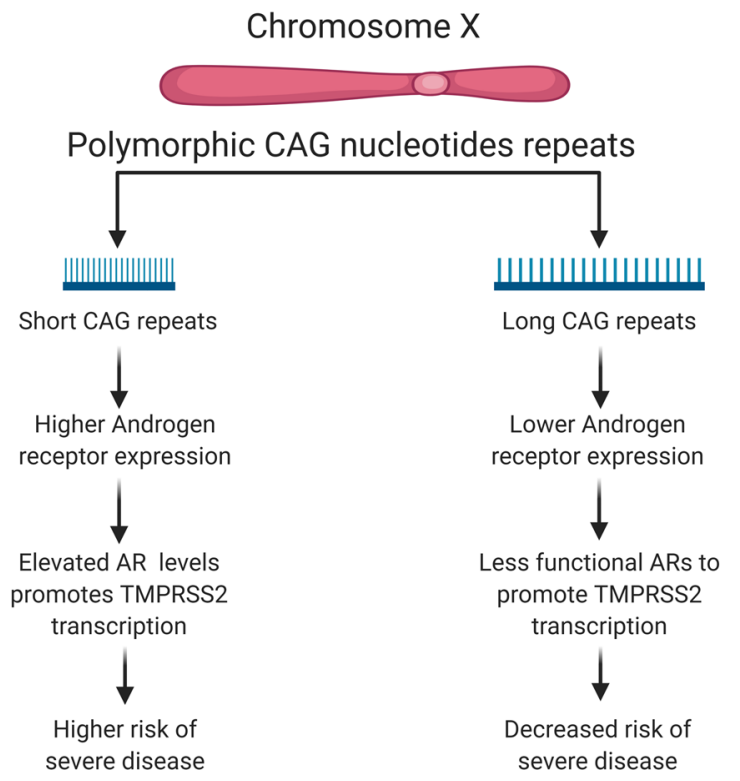

Fig. 2 Theoretical mechanisms suggesting CAG repeats length and associated androgen sensitivity as a predictor for COVID-19 disease severity

androgen-deprived patients would have a reduced number of activated androgen receptors to promote TMPRSS2 transcription and, thus, a decreased risk for SARS-CoV2 entry. Nevertheless, reported data from Italy and Germany suggest a contradictory outcome. Low testosterone levels can be observed in the majority of COVID-19 intensive care patients [15] and can predict poor prognosis and mortality [16]. While both studies have limitations such as 
Table 1 Drugs investigated as a line of treatment for COVID-19 infection, their primary targets, common indications, and proposed mechanism of action for COVID-19 treatment. Obtained from drugbank.ca

\begin{tabular}{|c|c|c|c|}
\hline Drug & Main targets & Primary indication & Mechanism of action \\
\hline Hydroxychloroquine & TLR-7, TLR-9, ACE2 & $\begin{array}{l}\text { Malaria prophylaxis and } \\
\text { uncomplicated malaria }\end{array}$ & $\begin{array}{l}\text { Inhibits terminal glycosylation } \\
\text { of ACE2. }\end{array}$ \\
\hline Nitric oxide & GUCY1A2, MT1A, IDO1 & Hypoxic respiratory failure (neonates) & Inhibition of androgen receptors. \\
\hline Dexamethasone & $\begin{array}{l}\text { Glucocorticoid receptors, NR0B1, Annexin } \\
\text { A1, NOS2, NR1I2 }\end{array}$ & $\begin{array}{l}\text { Bacterial infection; inflammatory } \\
\text { conditions }\end{array}$ & Regulates testosterone synthesis. \\
\hline
\end{tabular}

lack of control groups or testosterone levels prior to infection, the results warrant consideration. Typically, androgen levels are correlated to androgen sensitivity, but many factors can affect this association [17]. For instance, although testosterone levels are known to drop with age, there is no exact threshold that predicts androgen-sensitive phenotypes, and treatments are mostly based on symptomatology [18]. A possible modulator that could also mediate SARS-CoV2 infection is inflammation. Proinflammatory cytokines and systemic inflammatory processes are associated with low androgens levels in young and older men $[19,20]$. In addition, there is evidence that interindividual variation in androgen receptor sensitivity due to cysteine adenine guanine (CAG) polymorphisms can account for sensitivity symptoms even with 'low' testosterone levels [21, 22]

The androgen receptor has three main functional domains: the transactivation domain, the DNA-binding domain, and the ligand-binding domain. The N-terminal transactivation domain harbors a polymorphic CAG nucleotide repeat segment. Interestingly, the length of polymorphic CAG nucleotides repeats is associated with the prostate cancer pathophysiology, as shorter CAG repeats inversely correlate to androgen receptor expression and subsequently increase the risk of prostate cancer [12]. Increased androgen receptor expression might lead to a higher risk of acquiring a severe COVID-19 disease by promoting TMPRSS2 transcription (Fig. 2). Moreover, CAG repeat length was indicated as a mechanism behind racial variations noticed for the COVID-19 mortality rate. For example, African Americans have been disproportionately affected by SARS-COV2 compared to other ethnic groups in the U.S. This ethnic group seems to have a higher risk of developing progressive prostate cancer and display shorter CAG repeats [4, 23]. In vitro diagnostic test clinical trial based on CAG repeats length is currently ongoing to evaluate COVID-19 disease severity (Table 2). It is important to notice that, to the best of our knowledge, the effects of the length of the polymorphic CAG repeat sequence in pulmonary tissue are still unknown and no clinical data are available to support this hypothesis. Thus, the results from the ongoing trials are vital for evaluating the potential of this mechanism as a COVID-19 severity marker.

\section{Androgen suppression targeted treatment for COVID-19}

Since the start of the COVID-19 pandemic, various drugs have been proposed for treatment [24-26], but there is still no universal therapy approved. However, some medications (Table 1) have received attention due to their supposedly beneficial effects such as Hydroxychloroquine, Nitric oxide (NO), and dexamethasone. Hydroxychloroquine, an antimalarial drug, was shown to limit SARS-COV2 infections and prevent the virus entry [27, 28]. This drug was initially granted temporary FDA approval but was later revoked due to adverse effects and reported mortality [29]. However, the link to androgen's role might be significant. There is evidence that Hydroxychloroquine can also decrease androgens secretion progressively with the duration of treatment [30].

Similarly, NO affects androgen receptor activity. NO production and actions are dependent to some extent on androgen receptors and blocking androgen receptors reduces NO production [31]. Moreover, NO decreases androgen receptor promoter actions [32], which can subsequently affect TMPRSS2 and ACE 2 expression limiting the viral ability to enter host cells. NO has been shown to suppress SARS-COV2 replication [33]. In addition, NO affects the virus spike proteins and the interactions with ACE2, suggesting a multifunctional role against COVID-19 [34]. Taken together, these results indicate that androgen pathways might be the primary mechanism behind the observed NO beneficial outcome.

Recently, preliminary results from the Randomized Evaluation of COVID-19 therapy (RECOVERY) trial have been labeled as a scientific breakthrough and received international praise due to its promising results. Dexamethasone, a glucocorticosteroid drug, reduced the mortality rate by one-third in mechanically ventilated patients and by one-fifth for those receiving oxygen without ventilation [26]. Notably, dexamethasone has been shown to 
lower testosterone synthesis in animal models $[35,36]$ and human patients [36]. Lower androgen levels might be a contributor to dexamethasone observed beneficial effects; however, these preliminary results should be interpreted with caution.

Finally, high-throughput screening to identify compounds able to reduce ACE-2 levels revealed screening hits commonly can target androgen signalling pathway. Moreover, androgen inhibitors were able to reduce ACE2 levels suggesting beneficial effects of this approach [37]. Ongoing clinical trials demonstrate the therapeutic potential of androgen suppression (Table 2). As most of these treatments are well-known and globally available, if approved, they can provide accessible and efficient COVID-19 therapies.

In summary, androgen's TMPRSS2-mediated actions can explain both the low fatalities observed in prepubertal children and the differences between sexes regarding SARS-COV2 infection. Androgen sensitivity might be a critical factor in determining COVID-19 disease severity, and sensitivity tests can, therefore, help in predicting patient outcomes. There is still a large potential for development of androgen suppression-based treatments for COVID-19, but ongoing trials will provide valuable knowledge that can lead to improved therapies.

Acknowledgements Figures were created with the Biorender Software.

Funding T.C.M. is supported by the Kungl Vetenskapssamh Scholarship (Royal Society of Arts and Scientists), provided by Uppsala University, Sweden. H.B.S. is supported by the Swedish Research Council, the Swedish Brain Research Foundation, and by the FAT4BRAIN project funding from the European Union's Horizon 2020 research and innovation program [grant \#857394]. The funders had no role in the design of the study or in the writing of the paper. Open access funding provided by Uppsala University.

Author contributions M.S.M. and T.C.M contributed with conceptualization, investigation, and writing of the original draft. H.B.S contributed with conceptualization, supervision and funding acquisition. All authors reviewed and approved the final version of the paper.

\section{Compliance with ethical standards}

Conflict of interest The authors declare that they have no conflict of interest.

Publisher's note Springer Nature remains neutral with regard to jurisdictional claims in published maps and institutional affiliations.

Open Access This article is licensed under a Creative Commons Attribution 4.0 International License, which permits use, sharing, adaptation, distribution and reproduction in any medium or format, as long as you give appropriate credit to the original author(s) and the source, provide a link to the Creative Commons license, and indicate if changes were made. The images or other third party material in this article are included in the article's Creative Commons license, unless 
indicated otherwise in a credit line to the material. If material is not included in the article's Creative Commons license and your intended use is not permitted by statutory regulation or exceeds the permitted use, you will need to obtain permission directly from the copyright holder. To view a copy of this license, visit http://creativecommons. org/licenses/by/4.0/.

\section{References}

1. R. Castagnoli, M. Votto, A. Licari, I. Brambilla, R. Bruno, S. Perlini et al. Severe Acute respiratory syndrome coronavirus 2 (SARS-CoV-2) infection in children and adolescents: a systematic review. JAMA Pediatrics. American Medical Association, 882-889 (2020). https://doi.org/10.1001/jamapediatrics. 2020.1467

2. N. Sharifi, C.J. Ryan Editorial: Androgen hazards with COVID19. Endocrine-Related Cancer. BioScientifica Ltd.; 2020. E1-E3. https://doi.org/10.1530/ERC-20-0133

3. R. Channappanavar, C. Fett, M. Mack, P.P. Ten Eyck, D.K. Meyerholz, S. Perlman, Sex-Based Differences in Susceptibility to Severe Acute Respiratory Syndrome Coronavirus Infection. J. Immunol. 198, 4046-4053 (2017). https://doi.org/10.4049/ jimmunol.1601896

4. C.G. Wambier, A. Goren, S. Vaño-Galván, P.M. Ramos, A. Ossimetha, G. Nau et al. Androgen sensitivity gateway to COVID-19 disease severity. Drug Dev Res. Wiley-Liss Inc.; 2020. https://doi.org/10.1002/ddr.21688

5. M. Hoffmann, H. Kleine-Weber, S. Schroeder, N. Krüger, T. Herrler, S. Erichsen et al. SARS-CoV-2 Cell Entry Depends on ACE2 and TMPRSS2 and Is Blocked by a Clinically Proven Protease Inhibitor. Cell 181, 271-280.e8 (2020). https://doi.org/ 10.1016/j.cell.2020.02.052

6. A. Goren, S. Vaño-Galván, C.G. Wambier, J. McCoy, A. GomezZubiaur, O.M. Moreno-Arrones et al. A preliminary observation: Male pattern hair loss among hospitalized COVID-19 patients in Spain - A potential clue to the role of androgens in COVID-19 severity. J Cosmetic Dermatol. Blackwell Publishing Ltd; 2020. 1545-1547. https://doi.org/10.1111/jocd.13443

7. C.G. Wambier, S. Vaño-Galván, J. McCoy, A. Gomez-Zubiaur, S. Herrera, Á. Hermosa-Gelbard et al. Androgenetic alopecia present in the majority of patients hospitalized with COVID-19: The "Gabrin sign.”. J. Am. Acad. Dermatol 83, 680-682 (2020). https://doi.org/10.1016/j.jaad.2020.05.079

8. B. Lin, C. Ferguson, J.T. White, S. Wang, R. Vessella, L.D. True et al. Prostate-localized and Androgen-regulated Expression of the Membrane-bound Serine Protease TMPRSS2. Cancer Res. 59 (17), 4180-4184 (1999)

9. J.M. Lucas, L. True, S. Hawley, M. Matsumura, C. Morrissey, R. Vessella et al. The androgen-regulated type II serine protease TMPRSS2 is differentially expressed and mislocalized in prostate adenocarcinoma. J. Pathol. 215, 118-125 (2008). https://doi.org/ 10.1002/path.2330

10. L. Mikkonen, P. Pihlajamaa, B. Sahu, F.P. Zhang, O.A. Jänne, Androgen receptor and androgen-dependent gene expression in lung. Mol. Cell Endocrinol. 317, 14-24 (2010). https://doi.org/10. 1016/j.mce.2009.12.022

11. M. Montopoli, S. Zumerle, R. Vettor, M. Rugge, M. Zorzi, C.V. Catapano et al. Androgen-deprivation therapies for prostate cancer and risk of infection by SARS-CoV-2: a population-based study ( $\mathrm{N}=4532$ ). Ann. Oncol. 31, 1040-1045 (2020). https://doi.org/ 10.1016/j.annonc.2020.04.479

12. E. Giovannucci, M.J. Stampfer, K. Krithivas, M. Brown, A. Brufsky, J. Talcott et al. The CAG repeat within the androgen receptor gene and its relationship to prostate cancer. Proc. Natl
Acad. Sci. USA 94, 3320-3323 (1997). https://doi.org/10.1073/ pnas.94.7.3320

13. M.E. Sawaya, A.R. Shalita, Androgen receptor polymorphisms (CAG repeat lengths) in androgenetic alopecia, hirsutism, and acne. J. Cutan. Med. Surg. 3, 9-15 (1998). https://doi.org/10. $1177 / 120347549800300103$

14. A.M. Hillmer, S. Hanneken, S. Ritzmann, T. Becker, J. Freudenberg, F.F. Brockschmidt et al. Genetic variation in the human androgen receptor gene is the major determinant of common early-onset androgenetic alopecia. Am. J. Hum. Genet 77, 140-148 (2005). https://doi.org/10.1086/431425

15. M. Schroeder, B. Tuku, D. Jarczak, A. Nierhaus, T. Bai, H. Jacobsen et al. The majority of male patients with COVID-19 present low testosterone levels on admission to Intensive Care in Hamburg, Germany: a retrospective cohort study. medRxiv. 2020; 2020.05.07.20073817. https://doi.org/10.1101/2020.05.07.20073817

16. G. Rastrelli, V. Di Stasi, F. Inglese, M. Beccaria, M. Garuti, D. Di Costanzo et al. Low testosterone levels predict clinical adverse outcomes in SARS-CoV-2 pneumonia patients. Andrology 00, 1-11 (2020). https://doi.org/10.1111/andr.12821

17. J.A. McBride, C.C. Carson, R.M. Coward, Testosterone deficiency in the aging male. Ther. Adv. Urol. 8, 47-60 (2016). https://doi.org/10.1177/1756287215612961

18. A. Morgentaler, M. Khera, M. Maggi, M. Zitzmann, Commentary: who Is a Candidate for Testosterone Therapy? A Synthesis of International Expert Opinions. J. Sex. Med. 11, 1636-1645 (2014). https://doi.org/10.1111/jsm.12546

19. J. Bobjer, M. Katrinaki, C. Tsatsanis, Y. Lundberg Giwercman, A. Giwercman. Negative association between testosterone concentration and inflammatory markers in young men: a nested cross-sectional study. PLoS ONE. 2013;8. https://doi.org/10.1371/ journal.pone.0061466

20. M. Maggio, S. Basaria, G.P. Ceda, A. Ble, S.M. Ling, S. Bandinelli et al. The relationship between testosterone and molecular markers of inflammation in older men. J Endocrinol Investig. 28 (11 Suppl Proceedings), 116-119 (2005).

21. R. Singh, L. Singh, K. Thangaraj, Phenotypic heterogeneity of mutations in androgen receptor gene. Asian J. Androl. 9, 147-179 (2007). https://doi.org/10.1111/j.1745-7262.2007.00250.x

22. M Zitzmann. The Role of the CAG Repeat Androgen Receptor Polymorphism in Andrology. Advances in the Management of Testosterone Deficiency (KARGER, Basel, 2008), 52-61. https:// doi.org/10.1159/000175843

23. J. McCoy, C.G. Wambier, S. Vano-Galvan, J. Shapiro, R. Sinclair, P.M. Ramos et al. Racial variations in COVID-19 deaths may be due to androgen receptor genetic variants associated with prostate cancer and androgenetic alopecia. Are anti-androgens a potential treatment for COVID-19? J Cosmetic Dermatol. Blackwell Publishing Ltd, 1542-1543 (2020). https://doi.org/10.1111/ jocd. 13455

24. R. Wu, L. Wang, H.C.D. Kuo, A. Shannar, R. Peter, P.J. Chou et al. An Update on Current Therapeutic Drugs Treating COVID19. Current Pharmacology Reports. Springer; 2020. 56-70. https://doi.org/10.1007/s40495-020-00216-7

25. M.I.I. Rabby, Current drugs with potential for treatment of covid19: a literature review. J. Pharm. Pharm. Sci. 23, 58-64 (2020). https://doi.org/10.18433/jpps31002

26. P. Horby, W.S. Lim, J. Emberson, M. Mafham, J. Bell, L. Linsell et al. Dexamethasone for COVID-19-Preliminary Report Effect of Dexamethasone in Hospitalized Patients with COVID-19Preliminary Report RECOVERY Collaborative Group*. medRxiv. 2020; 2020.06.22.20137273. https://doi.org/10.1101/2020. 06.22.20137273

27. M. Wang, R. Cao, L. Zhang, X. Yang, J. Liu, M. Xu et al. Remdesivir and chloroquine effectively inhibit the recently emerged novel coronavirus (2019-nCoV) in vitro. Cell Research. 
Springer Nature; 2020. 269-271. https://doi.org/10.1038/s41422020-0282-0

28. Z. Sahraei, M. Shabani, S. Shokouhi, A. Saffaei, Aminoquinolines against coronavirus disease 2019 (COVID-19): chloroquine or hydroxychloroquine. Int J. Antimicrob. Agents 55, 105945 (2020). https://doi.org/10.1016/j.ijantimicag.2020.105945

29. U.S. Food and Drug Administration. Coronavirus (COVID-19) update: FDA revokes emergency use authorization for chloroquine andhydroxychloroquine [news release]. 15 June 2020. Accessed at www.fda.gov/news-events/press-announcements/coronavirus-covid19-update-fda-revokesemergency-use-authorization-chloroquine-and on 16 July 2020

30. W.G. Nicola, M.I. Khayria, M.M.H. Osfor, Plasma testosterone level and the male genital system after chloroquine therapy. Boll. Chim. Farm. 136, 39-43 (1997)

31. L. Gu, D. Lian, Y. Zheng, W. Zhou, J. Gu, X. Liu, Echinacoside-induced nitric oxide production in endothelial cells: Roles of androgen receptor and the PI3K-Akt pathway. Int J. Mol. Med. 45, 1195-1202 (2020). https://doi.org/10.3892/ijmm.2020.4476

32. M.V. Cronauer, Y. Ince, R. Engers, L. Rinnab, W. Weidemann, C. V. Suschek et al. Nitric oxide-mediated inhibition of androgen receptor activity: Possible implications for prostate cancer progression. Oncogene. 26, 1875-1884 (2007). https://doi.org/10. 1038/sj.onc. 1209984
33. S. Åkerström, M. Mousavi-Jazi, J. Klingström, M. Leijon, Å. Lundkvist, A. Mirazimi, Nitric Oxide Inhibits the Replication Cycle of Severe Acute Respiratory Syndrome Coronavirus. J. Virol. 79, 1966-1969 (2005). https://doi.org/10.1128/jvi.79.3. 1966-1969.2005

34. S. Åkerström, V. Gunalan, C.T. Keng, Y.J. Tan, A. Mirazimi, Dual effect of nitric oxide on SARS-CoV replication: Viral RNA production and palmitoylation of the $\mathrm{S}$ protein are affected. Virology. 395, 1-9 (2009). https://doi.org/10.1016/j.virol.2009. 09.007

35. L. Annie, G. Gurusubramanian, V. Kumar Roy, Dexamethasone mediated downregulation of PGC- $1 \alpha$ and visfatin regulates testosterone synthesis and antioxidant system in mouse testis. Acta Histochem. 121, 182-188 (2019). https://doi.org/10.1016/j.acthis. 2018.12.004

36. E.Z. Drobnis, A.K. Nangia. Immunosuppressants and male reproduction. Advances in Experimental Medicine and Biology. (Springer New York LLC, New York, NY), 2017) 179-210. 10.1007/978-3-319-69535-8_12

37. Z. Ghazizadeh, H. Majd, M. Richter, R. Samuel, S.M. Zekavat, H. Asgharian et al. Androgen Regulates SARS-CoV-2 Receptor Levels and Is Associated with Severe COVID-19 Symptoms in Men. bioRxiv Prepr Serv Biol. 2020; 2020.05.12.091082. https:// doi.org/10.1101/2020.05.12.091082 